\title{
A Comparison of the Pyrolysis of Olive Kernel Biomass in Fluidised and Fixed Bed Conditions
}

\author{
A. Al-Farrajii ${ }^{1}$ R. Marsh $^{1} \cdot$ J. Steer $^{1}$ (C)
}

Received: 20 May 2016/Accepted: 16 August 2016/Published online: 3 September 2016

(c) The Author(s) 2016. This article is published with open access at Springerlink.com

\begin{abstract}
The use of thermogravimetric analysis to describe biomass kinetics often uses bench top thermogravimetric analyser (TGA) analysers which are only capable of low heating rates. The aim of this research was to compare experimental fast pyrolysis of Olive kernels in a bespoke laboratory thermogravimetric fluidised bed reactor (TGFBR) characterised by rapid heating rates at high flow rates, compared to a smaller bench scale fixed bed TGA system. The pyrolysis in the TGFBR was analysed by using the isothermal kinetic approach and it was theorised that the pyrolysis decomposition reactions occurred by two mechanisms depending on the temperature, resulting in an activation energy of $67.4 \mathrm{~kJ} / \mathrm{mol}$ at temperatures below $<500{ }^{\circ} \mathrm{C}$ and $60.8 \mathrm{~kJ} / \mathrm{mol}$ at temperatures $>500{ }^{\circ} \mathrm{C}$. For comparison, a bench scale TGA was used to look at the thermal behaviour in different fixed bed thermal conditions giving a higher activation energy of $74.4 \mathrm{~kJ} / \mathrm{mol}$ due to the effect of external particle gas diffusion. The effect of biomass particle size $(0.3-4.0 \mathrm{~mm})$ on the conversion of biomass at different temperatures, was investigated between 300 and $660{ }^{\circ} \mathrm{C}$ in the TGFBR. The results suggested inhibition of internal gas diffusion was more important at lower temperatures, but in comparison had no significant effect when measured in the fixed bed TGA at lower heating rates. Bench top TGA analysis of pyrolysis is a rapid and valuable method, but is limited by smaller sample sizes and lower heating rates. In comparison, the conditions encountered with the laboratory scale TGFBR are more likely to be relevant to larger scale
\end{abstract}

J. Steer

SteerJ1@ cardiff.ac.uk

1 Cardiff School of Engineering, Cardiff University, Queen's Buildings, The Parade, Cardiff CF24 3AA, UK systems where heat distribution, heat transfer and mass diffusion effects play major roles in the reactivity of biomass.

Keywords Biomass - Pyrolysis - Processes - Fluidised bed · Olive kernel $\cdot$ Renewable

\section{Introduction}

Olive kernels are a co-product residue of agricultural activity in the Mediterranean region. Greece has the third largest Olive oil production industry in the world. About 400,000 tons of Olive kernels are produced annually [1]. Olive kernel is already exploited as a low cost solid biomass fuel $(0.046 £ / \mathrm{kg})$, and is mostly utilized for conventional combustion. However, Olive kernel has not yet utilised its full potential as alternative biofuel [2]. There is limited scientific research concerning the comparison of experimental fast pyrolysis of Olive kernels in fluidised bed and fixed bed systems, hence experimentation with this kind of biomass is of great interest.

Biomass pyrolysis is a viable route to produce renewable bio-oil and includes fundamental chemical reactions that are precursors of other thermal conversion technologies, such as combustion and gasification. Therefore, the study of the pyrolytic characteristics of biomass covers a key issue in demand for an advancement of biomass thermal conversion technologies.

There are two processes for biomass pyrolysis, slow pyrolysis and fast pyrolysis. Slow pyrolysis has been used for the production of charcoal, while fast pyrolysis has generally been used to obtain liquid products. Fast pyrolysis is described by high heating rates and rapid quenching 
of bio-oil products to terminate the secondary conversion of the products [3].

The pyrolysis characteristics of biomass, in particular measuring and deriving reaction kinetics, has been carried out using thermogravimetric analysis (TGA) by other researchers. This is normally undertaken via the measurement of variation of mass loss with time of a sample held in the TGA cell at a preset heating rate [4-7]. Other work has involved the development of reactors at a larger scales to determine the kinetics of biomass pyrolysis with larger sample sizes, determining conversion through the analysis of the yield of gas [8-11].

Traditional TGA can be considered to be a fixed bed technique with a relatively low heating rate compared to larger scale systems where biomass is added directly in the reactor at the reaction temperature so the particle heating rate is significantly greater. Meanwhile, the chemical processes in TGA are affected by the interfacial gas diffusion between the reactor space and the solid sample inside the TGA cell [12]. Other authors have noted the effect of the heating rate on the reaction kinetics in a TGA, which limits how comparable these results are with high heating rate systems such as fluidised bed or circulating bed gasifiers [13]. The kinetic parameters represented by the order of reaction or the activation energy may be so misleading that, if used in scaling up, it may result in problems with plant operation. It is therefore essential to make a careful study of the interaction to eliminate physical effects from purely chemical processes [14]. The pyrolysis of biomass involves the transport of gas and heat from the external bulk gas phase to the internal particle surface, where the chemical reactions take place. Moreover, the intrinsic rate, i.e. the rate of the chemical reaction step, free from heat and mass transfer limitations, is of considerable importance. Therefore, it is valuable to develop an apparatus for the kinetic study of biomass pyrolysis that has the same principle of measurement, but it is dealing with a fluidised bed and operating under a fast heating rate regime.

The thermogravimetric fluidised bed reactor (TGFBR), designed and fabricated in the School of Engineering at Cardiff University, used in the present study was capable of using larger sample sizes up to $60 \mathrm{~g}$ per run, compared with up to $20 \mathrm{mg}$ in the bench scale TGA. Furthermore, the reactor operates under isothermal conditions by using impervious alumina porcelain (IAP) as a heat transfer medium in the preheater. This paper compares the effects of particle size and temperature on pyrolysis kinetics under fixed bed conditions using a conventional bench scale TGA and under fluidised bed conditions using a novel thermogravimetric fluidisation system (TGFBR) equipped with built-in load cells for the dynamic measurement of biomass conversion. The aim of this work was to investigate the influence of heating rates and heat/mass transfer effects on the kinetic analyses of the results obtained in these different systems to describe and understand the importance of the bed conditions on the effect of biomass pyrolysis.

\section{Kinetic Methods}

The kinetic study attempts to demonstrate how the thermal decomposition occurs by finding the best kinetic model that fits and describes the mechanism of the reaction to determine the kinetic parameters. This is crucial to the design, build and operation of a large scale industrial reactor for the Olive kernel biomass.

In solid state kinetic analysis, it is appropriate to describe the reaction in terms of the conversion, $\mathrm{X}$ defined by Eq. (1) [15]. Where $m_{o}$ is the initial mass of the sample, $\mathrm{m}$ is the instantaneous mass of the pyrolysis sample, and $\mathrm{m}_{\mathrm{f}}$ is the final residual mass.

$X=\frac{m_{O}-m}{m_{O}-m_{f}}$

Activation energy describes the energy required for the reaction to occur [12]. It is one of the most important kinetic parameters for evaluating the reactivity and can be determined using the model-free/iso-conversional method, or model-fitting method as used in this study. Since the pyrolysis of Olive kernel in the TGFBR is a heterogeneous solid state reaction, the universal kinetics of the thermal decomposition of biomass are expressed by Eq. (2) [16], where $\mathrm{T}$ is the reaction temperature; $\mathrm{t}$ is the reaction time; $f(X)$ is the differential reaction model; $X$ is the conversion; and $\mathrm{k}(\mathrm{T})$ is the temperature dependant reaction rate that can be expressed by the Arrhenius Eq. (3), where $E_{a}$ is the activation energy, $\mathrm{A}$ is the pre-exponential factor and $\mathrm{R}$ is the universal gas constant.

$\frac{d X}{d t}=k(T) f(X)$

$k(T)=A \exp \left[\frac{-E a}{R T}\right]$

A model fitting method was used for the isothermal tests in the TGFBR, to calculate the kinetic parameters based on the integration of Eq. (2) to derive the Eq. (4) and define the term $\mathrm{G}(x)$ in Eq. (5). This integral term is represented by the model equations shown in Table 1 and by conducting experiments at a range of isothermal temperatures a plot of lnk versus $1 / \mathrm{T}$ was obtained to derive the activation energy from the slope of the plot according to Eq. (5) with the most suitable method determined by the best linearity fit [17]. 
Table 1 Typical reaction mechanisms for heterogeneous solid-state reaction

\begin{tabular}{|c|c|c|c|}
\hline Symbol & Reaction mechanism & $f(x)$ & $\mathrm{G}(\mathrm{x})$ \\
\hline G1 & One-dimensional diffusion, 1D & $1 / 2 \mathrm{x}$ & $x^{2}$ \\
\hline $\mathrm{G} 2$ & Two-dimensional diffusion (Valensi) & {$[-\ln (1-x)]^{-1}$} & $x+(1-x) \ln (1-x)$ \\
\hline G3 & Three-dimensional diffusion (Jander) & $1.5(1-x)^{2 / 3}\left[1-(1-x)^{1 / 3}\right]^{-1}$ & {$\left[1-(1-x)^{1 / 3}\right]^{2}$} \\
\hline G4 & Three-dimensional diffusion $(\mathrm{G}-\mathrm{B})$ & $1.5\left[1-(1-\mathrm{x})^{1 / 3}\right]^{-1}$ & $1-2 x / 3-(1-x)^{2 / 3}$ \\
\hline G5 & Three-dimensional diffusion (A-J) & $1.5(1+x)^{2 / 3}\left[(1+x)^{1 / 3}-1\right]^{-1}$ & {$\left[(1+x)^{1 / 3}-1\right]^{2}$} \\
\hline G6 & Nucleation and growth $(\mathrm{n}=2 / 3)$ & $1.5(1-\mathrm{x})[-\ln (1-\mathrm{x})]^{1 / 3}$ & {$[-\ln (1-x)]^{2 / 3}$} \\
\hline G7 & Nucleation and growth $(\mathrm{n}=1 / 2)$ & $2(1-x)[-\ln (1-x)]^{1 / 2}$ & {$[-\ln (1-\mathrm{x})]^{1 / 2}$} \\
\hline G8 & Nucleation and growth $(n=1 / 3)$ & $3(1-x)[-\ln (1-x)]^{2 / 3}$ & {$[-\ln (1-x)]^{1 / 3}$} \\
\hline G9 & Nucleation and growth $(\mathrm{n}=1 / 4)$ & $4(1-x)[-\ln (1-x)]^{1 / 3}$ & {$[-\ln (1-x)]^{1 / 4}$} \\
\hline G10 & Autocatalytic reaction & $\mathrm{x}(1-\mathrm{x})$ & $\ln [x /(1-x)]$ \\
\hline G11 & Mampel power law $(\mathrm{n}=1 / 2)$ & $2 x^{1 / 2}$ & $x^{1 / 2}$ \\
\hline G12 & Mampel power law $(\mathrm{n}=1 / 3)$ & $3 x^{2 / 3}$ & $x^{1 / 3}$ \\
\hline G13 & Mampel power law $(n=1 / 4)$ & $4 x^{3 / 4}$ & $x^{1 / 4}$ \\
\hline G14 & Chemical reaction $(\mathrm{n}=3)$ & $(1-x)^{3}$ & {$\left[(1-x)^{-2}-1\right] / 2$} \\
\hline G15 & Chemical reaction $(\mathrm{n}=2)$ & $(1-x)^{2}$ & $(1-x)^{-1}-1$ \\
\hline G16 & Chemical reaction $(\mathrm{n}=1)$ & $1-\mathrm{x}$ & $-\ln (1-x)$ \\
\hline G17 & Chemical reaction $(\mathrm{n}=0)$ & 1 & $\mathrm{x}$ \\
\hline G18 & Contraction sphere & $3(1-x)^{2 / 3}$ & $1-(1-x)^{1 / 3}$ \\
\hline G19 & Contraction cylinder & $2(1-x)^{1 / 2}$ & $1-(1-x)^{1 / 2}$ \\
\hline
\end{tabular}

$A-J$ Anti-Jander, $G-B$ Ginstling-Brounshtein

$\int \frac{d x}{f(x)}=\int k(T) d t$

$G(x)=k(T) t$

$\ln k(T)=\ln (A)-E / R T$

In comparison, for the non-isothermal fixed bed TGA, The Coats-Redfern integral method was used to analyse the kinetic parameters $[18,19]$. At a constant heating rate the variation of temperature with time is given by Eq. (7):

$T=T_{o}+\beta t$

where $\beta$ heating is rate and $T_{o}$ is the initial temperature of the reaction, differentiating gives Eq. (8):

$\mathrm{dT}=\beta \mathrm{dt} \quad$ or $\quad \mathrm{dt}=\mathrm{dT} / \beta$

where the Coats-Redfern equation is represented by Eq. (9) [20].

$\ln \left(\frac{G(x)}{T^{2}}\right)=\ln \left(\frac{A R}{\beta E}\right)-\frac{E}{R T}$

Thus the terms, $\ln \left(G(x) / \mathrm{T}^{2}\right)$ versus $1 / \mathrm{T}$, were plotted to give a straight line with a slope $-E / R$ since $\ln (A R / \beta E)$, allowing the calculation of the activation energy. The integral model $G(x)$ was substituted from Table 1 into Eq. (9) to determine if it described the reaction depending on its linearity fit using the coefficient of determination $\left(\mathrm{R}^{2}\right)$.

\section{Experimental}

\section{Olive Kernel Biomass}

Olive kernel biomass is a residue of Olive production received as coarse particles less than $5 \mathrm{~mm}$ and ground using a laboratory disc mill, model Lm1 pulverising mill. The ground biomass was screened to sizes ranges of 300-500, 500-710, 710-1180 and 1180-1400 $\mu \mathrm{m}$ using sieves.

According to BS EN 18134-2:2013 (moisture content), BS EN ISO 18123: (volatile matter content) and BS EN 14775:2009 (ash content) the proximate analysis was determined. Fixed carbon (FC) is defined as the solid residue left after determination of volatile material, ash and moisture content of the Olive kernel. The calculation of fixed carbon was done in this study based on difference using Eq. (10): $\begin{aligned} \mathrm{FC}[\%]= & 100-\text { moisture content }(\%)-\text { ash content }(\%) \\ & - \text { volatiles }(\%)\end{aligned}$ 
Table 2 details the characterisation of the Olive kernel used: its proximate analysis and higher heating value.

\section{Fixed Bed Thermogravimetric Analysis (TGA)}

The fixed bed bench top TGA analysis of Olive kernel biomass pyrolysis was carried out using a Mettler TGA851 in a nitrogen atmosphere with a flow rate of $50 \mathrm{ml} / \mathrm{min}$, heating rate of $20^{\circ} \mathrm{C} / \mathrm{min}$ and a $10 \mathrm{mg}$ sample size. The four sieved size classifications of the Olive kernel sample used in this study were as follows:

1. $300-500 \mu \mathrm{m}$.

2. $500-710 \mu \mathrm{m}$.

3. $710-1180 \mu \mathrm{m}$.

4. $1180-1400 \mu \mathrm{m}$.

\section{Fluidised Bed Thermogravimetric Pyrolysis Reactor (TGFBR)}

The fast pyrolysis of Olive kernel was carried out in a laboratory scale fluidised bed reactor with a load cell. Figure 1 shows a schematic diagram of the pyrolysis apparatus consisting of a stainless steel reactor with $83 \mathrm{~mm}$ internal diameter and a $1000 \mathrm{~mm}$ high. A perforated diffuser plate was made from stainless steel with thickness $5 \mathrm{~mm}$ and uniformly perforated with $151 \times 1 \mathrm{~mm}$ diameter holes to retain the bed fluidisation material. A perforated plate was used in this study because it improved the mixing significantly (less segregation tendency) compared to a porous plate [21]. The fluidiser was surrounded by a split tube furnace (three heating zones) with a maximum temperature of $1200{ }^{\circ} \mathrm{C}$. The fluidising nitrogen was passed through a $50 \mathrm{~mm}$ internal diameter $670 \mathrm{~mm}$ long tube containing IAP as a heat transfer medium. The tube was surrounded by an electrical preheater tube furnace, supplied by LTF. A PID controller was used for temperature control and to monitor the bed temperature thermocouple in the fluidised bed.

The fluidised bed was positioned on a bespoke platform load cell designed by Coventry Scale Company. The balance tolerance was $\pm 0.5 \mathrm{~g}$ with a weighing range up to $25 \mathrm{~kg}$. A multifunction weight indicator model DFW06XP was connected to a load cell and through a computer to record the mass change continuously at $1 \mathrm{~s}$ time intervals.

\section{Results}

\section{Fixed Bed Thermogravimetric Analysis (TGA)}

The pyrolysis results obtained from fixed bed thermogravimetric experiments were recorded as a function of the conversion $\mathrm{X}$, expressed in Eq. (1). The degree of conversion against temperature at a heating rate of $20^{\circ} \mathrm{C} / \mathrm{min}$ for the four particles size classifications of Olive kernel are shown in Fig. 2. Below $250{ }^{\circ} \mathrm{C}$ the mass change due to moisture loss occurred during the early heating period. The initial thermal decomposition of the Olive kernel started at $250{ }^{\circ} \mathrm{C}$, but the major decomposition region (active pyrolysis) happened between 260 and $356^{\circ} \mathrm{C}$. The majority of volatile decomposition, up to $80 \%$ of the overall mass conversion, occurred during this temperature range. Therefore, for conversion greater than $80 \%$, most of the remaining material is char. Considering only the TGA results, all particle size classifications exhibited the same trend. The effect of particle size on pyrolysis was investigated for four particle sizes as shown in Fig. 2 and demonstrated that particle size does not have an important influence on the TGA profile of the Olive kernel. A similar effect for Codium fragile (a marine biomass) has been reported by Daneshvar and Otsuka [22] for particle sizes from 75 to $1400 \mu \mathrm{m}$.

Biomass is composed of cellulose, hemicellulose, and lignin which due to essential differences in the structure of these constituents can be identified and distinguished during thermogravimetric analysis [23]. According to Yang et al. [24] hemi-cellulose decomposes mainly at $220-315^{\circ} \mathrm{C}$, cellulose at $315-400{ }^{\circ} \mathrm{C}$, while lignin decomposes over a wide temperature range from 160 to $900{ }^{\circ} \mathrm{C}$. Figure 3 shows the differential thermogravimetric analysis curve (DTG) at heating rate $20{ }^{\circ} \mathrm{C} / \mathrm{min}$ gives the differential rate of conversion, $\mathrm{dm} / \mathrm{dt}$, for particle sizes 300-500, 500-710, 710-1180 and 1180-1400 $\mu \mathrm{m}$. The first peak below $100{ }^{\circ} \mathrm{C}$ corresponds to the moisture in the sample; the second peak between 200 and $300{ }^{\circ} \mathrm{C}$ suggests
Table 2 Proximate analysis and higher heating value of Olive kernel

\begin{tabular}{llllll}
\hline Particle size $(\mu \mathrm{m})$ & Fixed carbon & Volatile matter & Ash & Moisture & HHV $(\mathrm{MJ} / \mathrm{kg})$ \\
\hline Proximate analysis (wt\%) & 17.1 & 69.0 & & & \\
$300-500$ & 17.5 & 68.8 & 0.4 & 13.5 & 19.3 \\
$500-710$ & 17.7 & 69.0 & 0.3 & 13.4 & 19.2 \\
$710-1180$ & 17.9 & 68.6 & 0.5 & 12.9 & 19.3 \\
$1180-1400$ & 18.0 & 68.2 & 0.5 & 13.0 & 19.3 \\
As received & & 0.6 & 13.3 & 19.2 \\
\hline
\end{tabular}


Fig. 1 Thermogravimetric fluidized bed reactor TGFBR

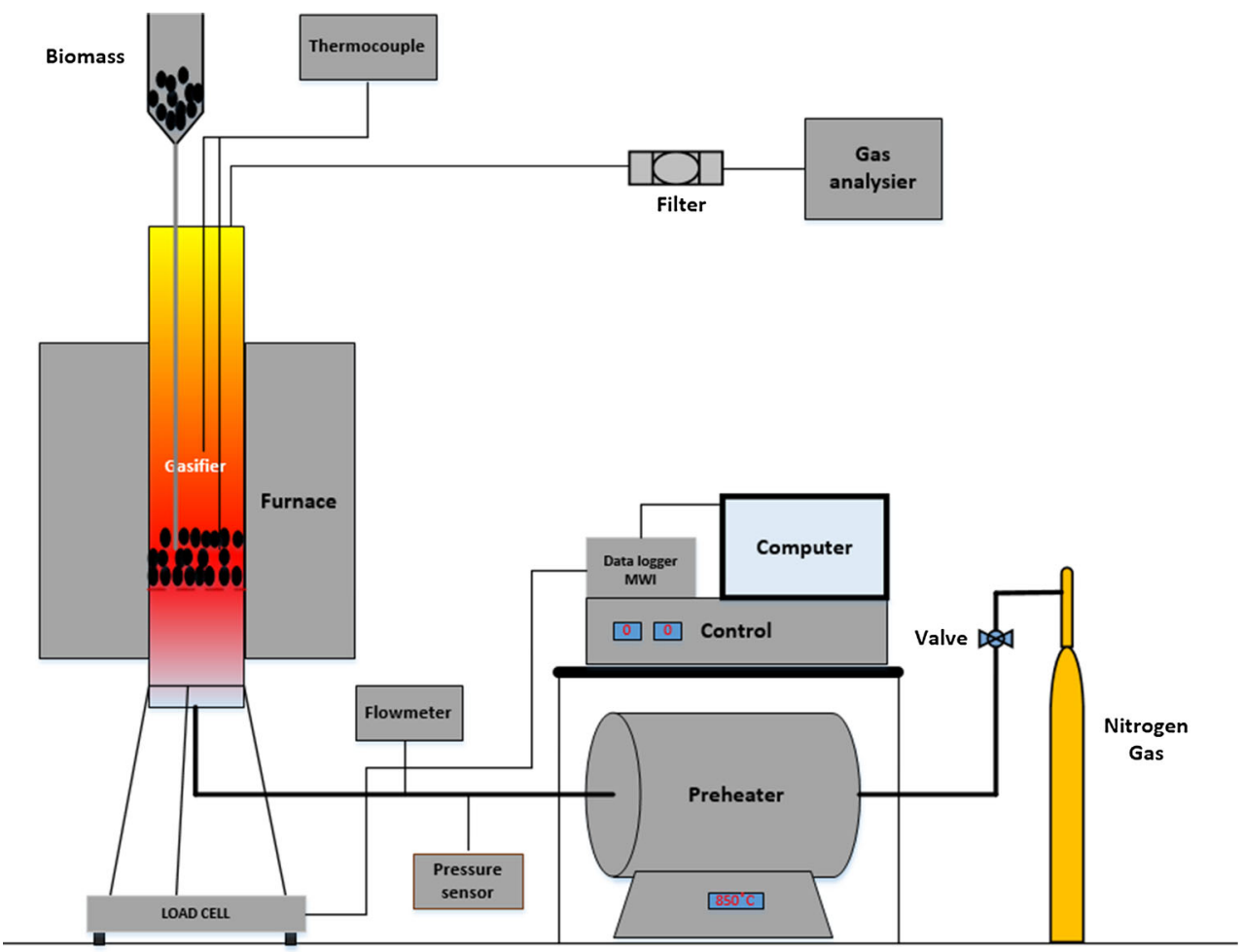

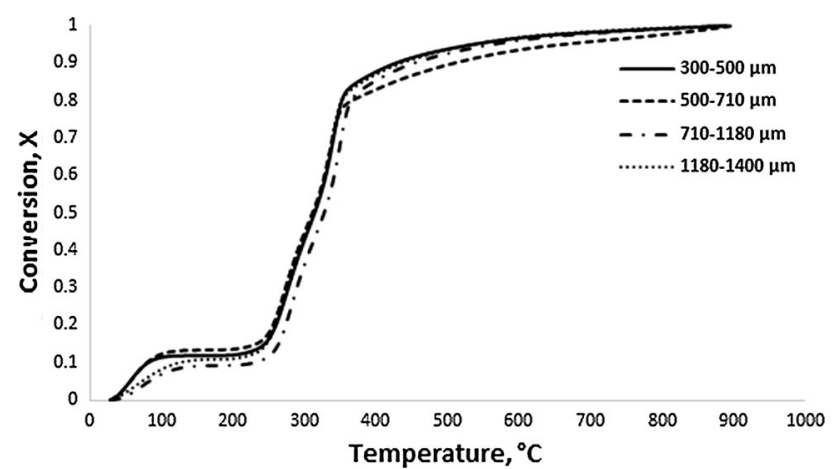

Fig. 2 Relationship between mass conversion and temperature for olive kernel of different particle size at heating rate $20{ }^{\circ} \mathrm{C} / \mathrm{min}$, sample weight of about $10 \mathrm{mg}$ (TGA), nitrogen flow rate was $50 \mathrm{ml} /$ $\min$

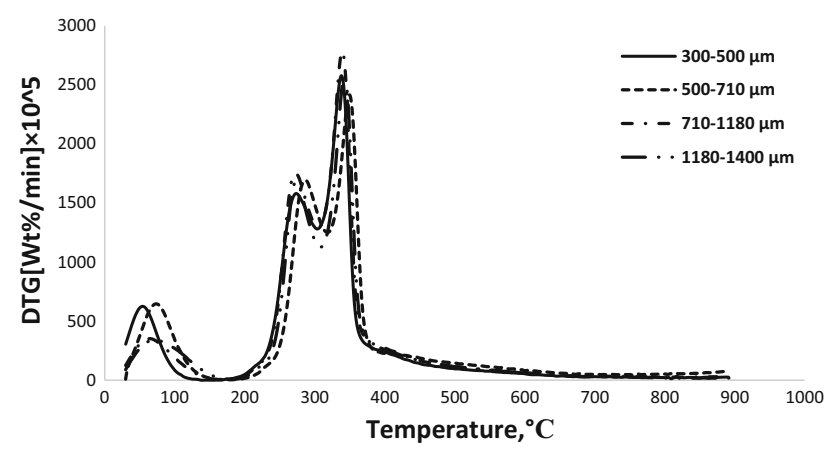

Fig. 3 Variation of the instantaneous rate of reaction with temperature at $20{ }^{\circ} \mathrm{C} / \mathrm{min}$ heating rate for pyrolysis of olive kernel the thermal decomposition of hemicellulose; and the final peak between 300 and $380{ }^{\circ} \mathrm{C}$ corresponds to cellulose decomposition. The slow rate of mass loss at higher temperatures $>380{ }^{\circ} \mathrm{C}$ is consistent with lignin decomposition. Approximately the same trend of DTG has been reported by Kastanaki et al. [25] during the pyrolysis of Olive kernel and Jae et al. [26] through pyrolysis of maple wood.

\section{Fluidised Bed Reactor Thermogravimetric Analysis (TGFBR)}

The experimental measurements using the TGFBR were achieved at pre-set steady-state temperatures between 300 and $660{ }^{\circ} \mathrm{C}$, covering the chemically controlled regime area of thermal decomposition illustrated in Fig. 3. Prior to pyrolysis, the experimental work was started by heating the reactor to the required temperature ensuring that good bed fluidisation was achieved as determined by the measurement of the bed pressure drop against the superficial velocity of the gas flow. Silica sand was used as the inert fluidised bed material with a diameter of $500-600 \mu \mathrm{m}$ giving a measured minimum fluidisation velocity $\left(\mathrm{u}_{\mathrm{mf}}\right)$ of $0.06 \mathrm{~m} / \mathrm{s}$ [27]. After that, the air stream was stopped and the nitrogen stream flowed at the minimum fluidisation velocity $\left(\mathrm{u}_{\mathrm{mf}}\right)$ [28] until steady state temperature conditions inside the reactor were obtained. Olive kernel biomass was fed from the top of the reactor through a pipe into the hot fluidised bed as shown in Fig. 1. The amount of biomass 
used in each test was $40 \mathrm{~g}$ representing $10 \mathrm{wt} \%$ of the total bed material weight. The weight variation in TGFBR during the pyrolysis process was recorded online with the weighing indicators at $1 \mathrm{~s}$ time intervals. According to Choi et al. [29], bed particles should have terminal velocities larger than the superficial gas velocity to prevent elutriation loss of bed material. Therefore, during this study the superficial velocity was kept much lower than the terminal velocity $(0.89 \mathrm{~m} / \mathrm{s})$ and accordingly no significant losses of bed material were measured $(<0.1 \%)$ with the load cell.

\section{Influence of Nitrogen Flow on Pyrolysis Conversion Rate}

A fundamental issue in pyrolysis is the interaction of evolving nascent, hot pyrolysis vapours with the surrounding decomposing solid. The residence time of the vapour phase of pyrolysis products is affected by the nitrogen flow used for fluidisation, which alters the extent of secondary reactions such as cracking and char formation [8] and improves the heat transfer from fluid gas to the particle.

Olive kernel was pyrolysed under different conditions. Figure 4 shows the variation of the conversion with reaction time for the particle size classification between 1180 and $1400 \mu \mathrm{m}$ at temperature 300 and $500{ }^{\circ} \mathrm{C}$ using different fluidising gas flow velocities that were below the terminal fluidisation velocity condition for the silica sand used. The trend of biomass conversion at $300{ }^{\circ} \mathrm{C}$ for different flow velocities of $\mathrm{N}_{2}$ were the same, which suggests the inhibition of internal and external diffusion effects at this temperature, but there was no effect of increasing the flow velocity beyond $0.09 \mathrm{~m} / \mathrm{s}(30 \mathrm{l} / \mathrm{min})$ although a small deviation occurred with the $0.06 \mathrm{~m} / \mathrm{s}(201 / \mathrm{min})$ result which is thought to be due to limited silica sand fluidisation observed at the beginning of biomass addition.

At the higher temperature of $500{ }^{\circ} \mathrm{C}$, the rate of reaction determined from the slope of the conversion line showed a wide variation up to a velocity of $0.12 \mathrm{~m} / \mathrm{s}(40 \mathrm{l} / \mathrm{min})$, after which a much smaller variation occurred. This critical gas flow velocity represents the flow required to minimise the external diffusion inhibition on the reaction rate [10]. By operating the gas-solid reaction system at sufficiently high gas flow velocity and rate, the mass transfer effects could be minimised so that any further increase in the gas flow rate did not produce an increase in the overall reaction rate [30]. Therefore, a flow velocity of $0.12 \mathrm{~m} / \mathrm{s}$ (40 1/min) was chosen as the basis for all experimental work, representing the minimum gas velocity required to limit external diffusion.

\section{Effect of Particle Size}

In laboratory scale pyrolysis, particle size can have a significant effect on the reaction rate. When the particle size increases the temperature gradients inside the particle also increase, so that at any given time, the surface temperature is higher than that of the core, which can increase the solid yields with a corresponding decrease in liquid and gas yield [8]. In this study, Fig. 5 illustrates the influence of Olive kernel particle size on conversion at temperatures of 300 , 350,400 and $451{ }^{\circ} \mathrm{C}$. At this range of temperatures, it was observed that the conversion profile exhibited minimal differences for the particle sizes tested. Assuming the temperature and concentration of the produced gases were uniform, it was concluded that the rate of de-volatilisation occurred homogenously throughout the particle and the rate did not depend on the size of particle. Szekely et al. [30] reported the same explanation for gas solid reactions at low temperature. However, at higher temperatures between 500 and $660{ }^{\circ} \mathrm{C}$ as shown in Fig. 6, the influence of particle size was more obvious. When the particle size decreases the reaction time also decreases. One may therefore assume that at higher temperatures the effect of external diffusion is greater, therefore the effect of temperature gradient is greater leading to heat transfer limitations. The comparatively low thermal conductivity of biomass gives a low heating rate through larger particles
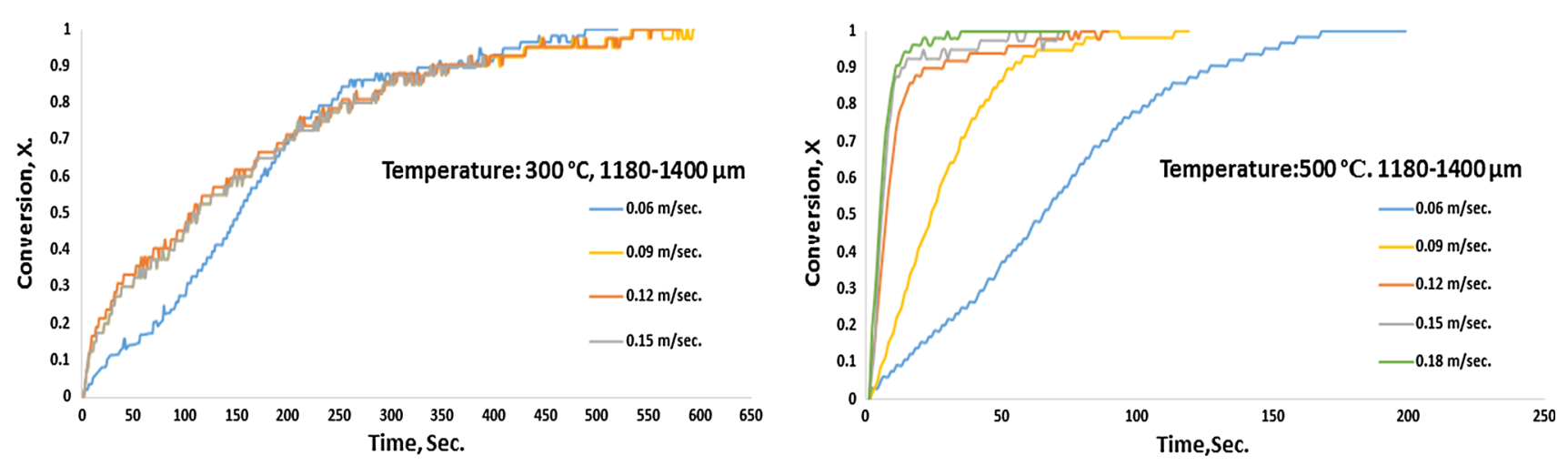

Fig. 4 Total weight conversion against reaction time in TGFBR at different flowrate, $\mathrm{T}=300$ and $500{ }^{\circ} \mathrm{C}$ 

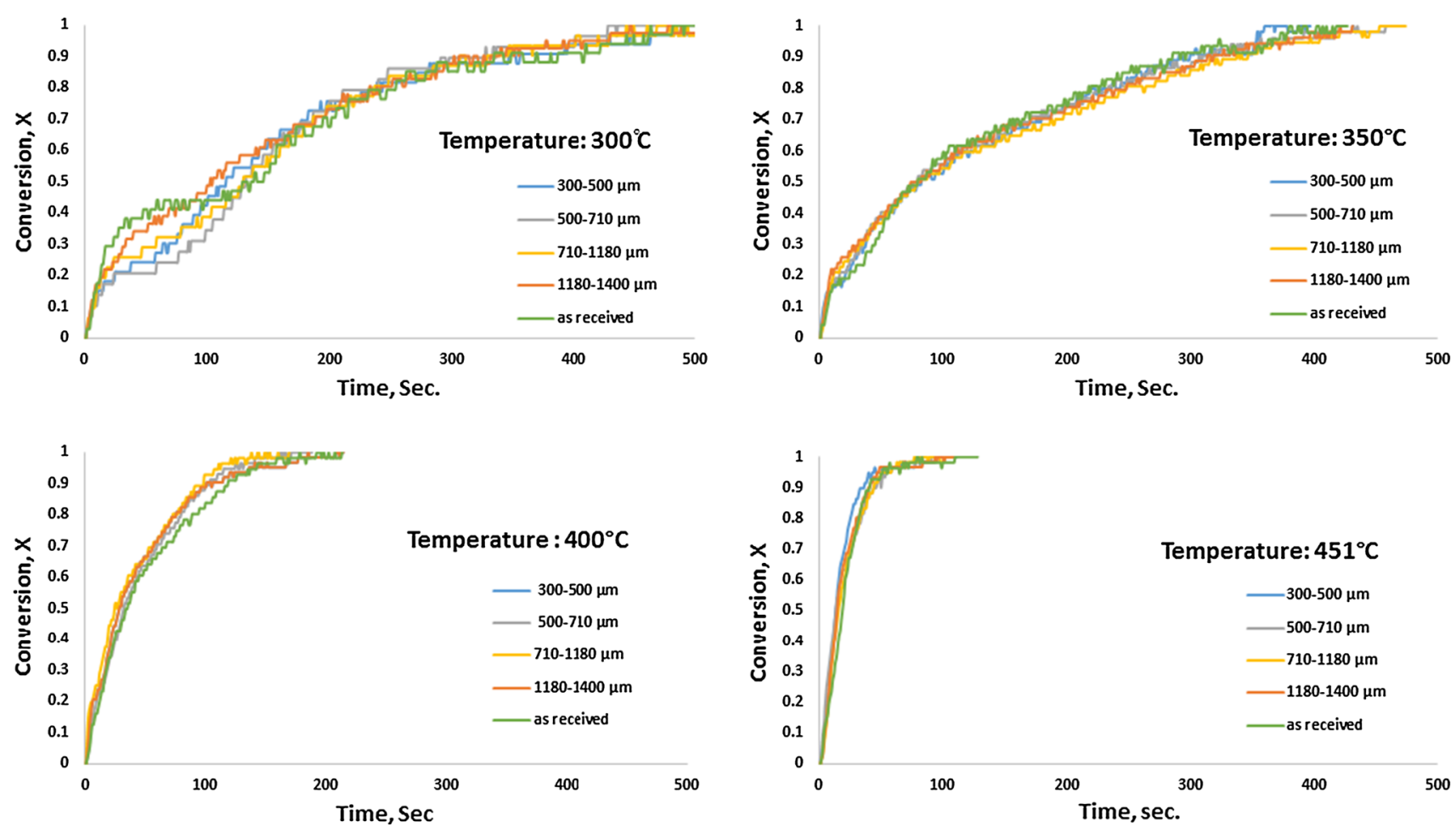

Fig. 5 Progress of conversion fractions against reaction time at temperatures $\left(300,350,400\right.$ and $\left.451{ }^{\circ} \mathrm{C}\right)$
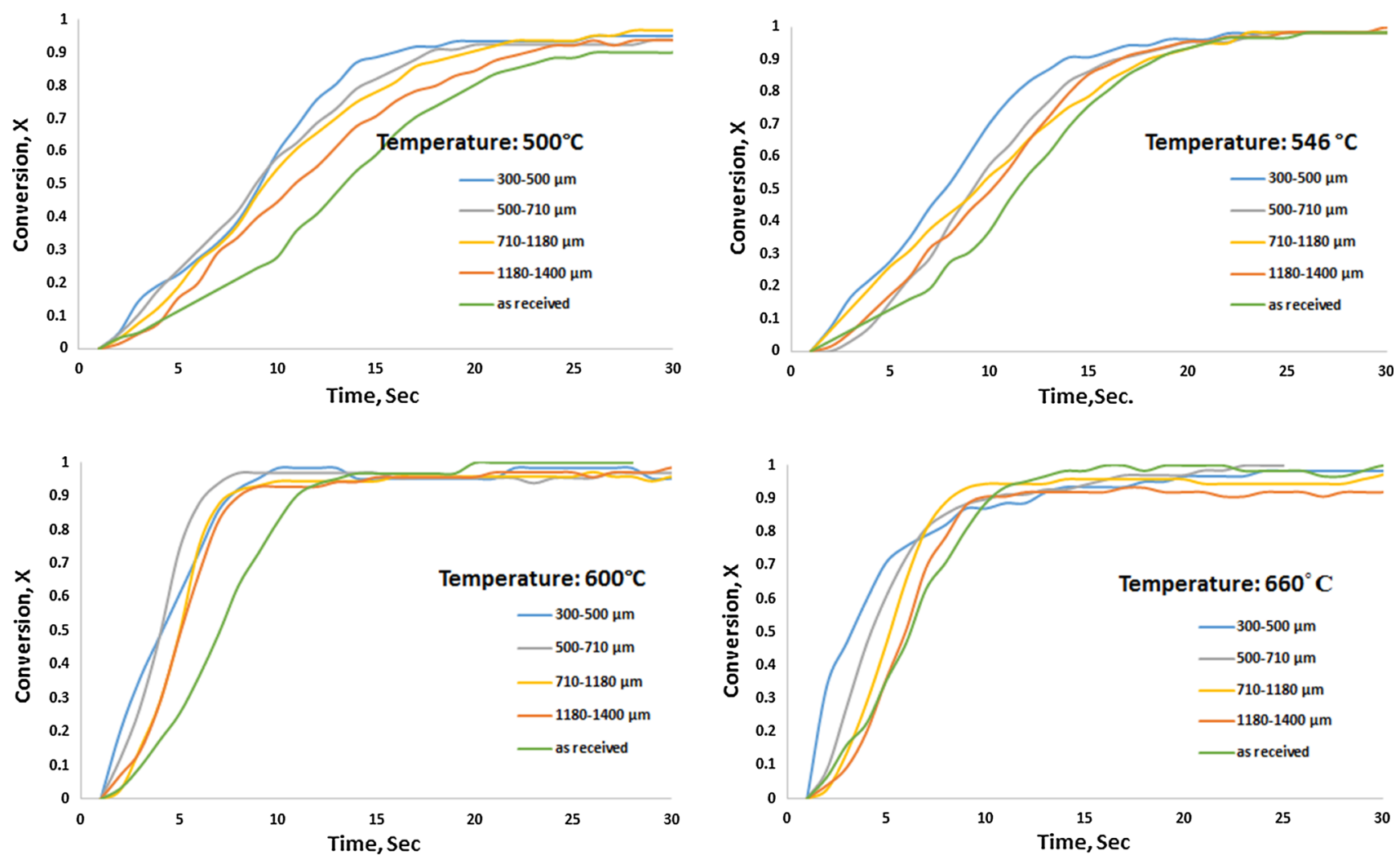

Fig. 6 Progress of conversion fractions against reaction time at temperatures $\left(500,546,600\right.$ and $\left.660{ }^{\circ} \mathrm{C}\right)$ 
which leads to increased char formation [31]. These results were consistent with findings reported in the literature where at low temperatures the limitation of the reaction rate is mainly due to chemical kinetics (up to about $400{ }^{\circ} \mathrm{C}$ ), while mass transport phenomena limit the reactions at higher temperatures [32].

\section{Effect of Temperature}

Figure 7 shows the effect of temperature on char yield as a percentage of the original Olive kernel mass. For the particle size classifications $(300-500,500-710,710-1180$, $1180-1400 \mu \mathrm{m}$ and the as received biomass) the char mass percent decreased from between 55 and $60 \mathrm{wt} \%$ at $300{ }^{\circ} \mathrm{C}$ to $9-12 \mathrm{wt} \%$ at $660{ }^{\circ} \mathrm{C}$. A sudden decrease in the char yield occurred between 300 and $350{ }^{\circ} \mathrm{C}$ ranging from $37 \%$ for the largest particle size (as received) to $28 \mathrm{wt} \%$ for the smallest size classification 300-500 $\mu \mathrm{m}$. In comparison, Zabaniotou et al. [33] reported that the Olive kernel char yield decreased with increasing temperature during pyrolysis to a minimum value of $33 \mathrm{wt} \%$ of sample and yields stabilised above $500{ }^{\circ} \mathrm{C}$.

There are two types of reaction through which the thermal degradation occurs: a comparatively slow decomposition and charring on heating at lower temperatures $<300{ }^{\circ} \mathrm{C}$ and a rapid devolatilization accompanied by the formation of levoglucosan from pyrolysis at higher temperatures. At temperatures $>302{ }^{\circ} \mathrm{C}$, cellulose and hemicellulose depolymerizes producing volatile products [34] as shown in Fig. 3. For this reason the significant weight percent change occurring between 300 and $350{ }^{\circ} \mathrm{C}$ is likely to be due to the increased devolatilization rate of hemicellulose and cellulose. The char formation decreases with increasing temperature due to further decomposition of biomass and there was little difference observed for the different classifications.

Figure 8 illustrates the influence of temperature on the conversion for all particle sizes of Olive kernel (300-500, 500-710, 710-1180, 1180-1400 $\mu \mathrm{m}$ and as received). As

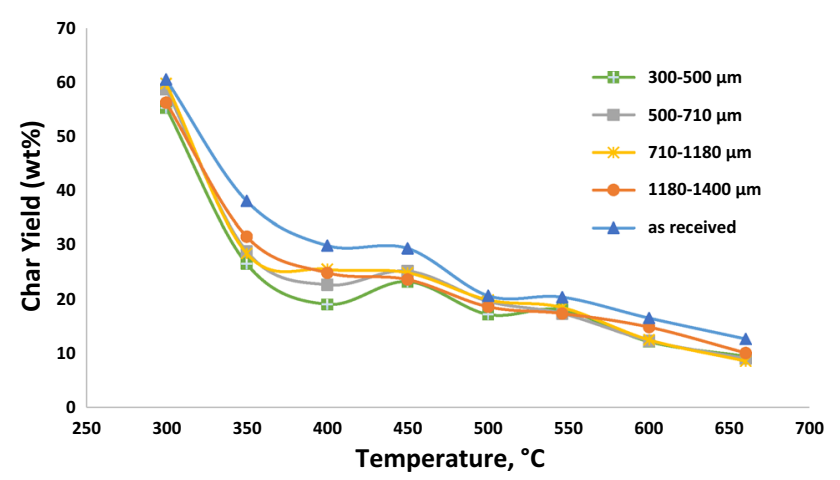

Fig. 7 Char yield as a function of temperature (TGFBR)

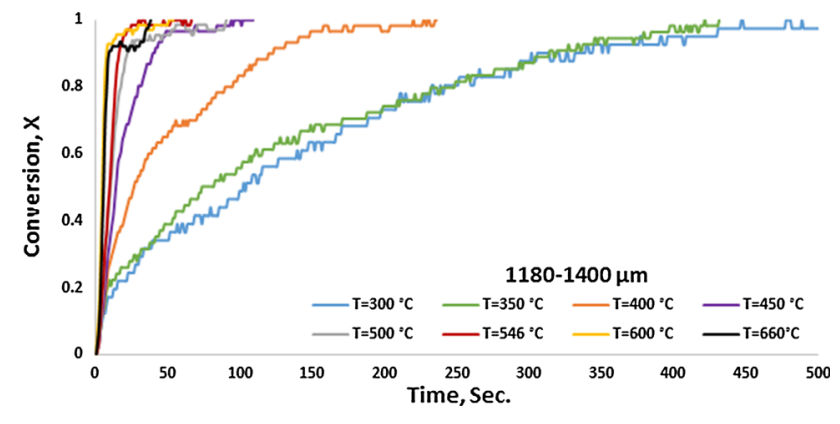

Fig. 8 Olive kernel conversion versus reaction time in TGFBR

expected, the completion time of pyrolysis reduced with increasing temperature for all particle sizes. At $300{ }^{\circ} \mathrm{C}$, the reaction time was $450 \mathrm{~s}$ reducing to less than $10 \mathrm{~s}$ for temperatures above $500{ }^{\circ} \mathrm{C}$; this suggests that the increase in temperature leads to a decreased yield of solid and an increased yield of gas product. The moderate temperature, high heat transfer to the biomass particles and short residence time of hot vapour in the reaction zone are the most significant characteristics of fast pyrolysis, used to describe processes with reaction times of only a few seconds or less, $[35,36]$. As shown in Fig. 8, the pyrolysis of Olive kernel in the TGFBR occurred under fast pyrolysis conditions.

\section{Kinetic Analysis of Pyrolysis of Olive Kernel}

Non-isothermal testing of Olive kernel was done in the TGA instrument with a $20{ }^{\circ} \mathrm{C} / \mathrm{min}$ heating rate. Several solid-state mechanisms (Table 1) were tested for a suitable fit by the Coats-Redfern method in order to determine the mechanisms responsible for the decomposition of biomass of particle size $1180-1400 \mu \mathrm{m}$ at conversion levels between $\mathrm{X}=0.2-0.8$, because the main conversion occurs in this study range. Equation (9) was applied separately to each model, the form of $G(x)$ giving a straight line with the highest correlation coefficient was considered to be the model function best representing the kinetic mass loss reaction. Table 3 shows the different reaction models and correlation coefficient fits obtained from the plots of $\ln \left(G(x) / \mathrm{T}^{2}\right)$ verses $1 / \mathrm{T}$ as illustrated in Fig. 9. From the slope of each line, the values of activation energies were obtained.

Table 3 revealed that the two dimensional diffusion model (G2) was the best fit. The high coefficient value (0.986) demonstrated a good fit and the activation energy of Olive kernel $(1180-1400 \mu \mathrm{m})$ measured $74.4 \mathrm{~kJ} / \mathrm{mol}$.

For the isothermal condition, Fig. 10 (low temperature $<500{ }^{\circ} \mathrm{C}$ ) and Fig. 11 (high temperature $\geq 500{ }^{\circ} \mathrm{C}$ ) illustrate the correlation of $G(x)$ against time at different reaction temperatures for 1180-1400 $\mu \mathrm{m}$ Olive kernel in the TGFBR. Based on the fitting accuracy, the most probable reaction models (Table 4) were selected from 
Table 3 Reaction model for olive kernel decomposition during fixed bed non-isothermal pyrolysis

\begin{tabular}{llllllllll}
\hline $\mathrm{G}(\mathrm{X})$ & $\mathrm{G} 2$ & $\mathrm{G} 3$ & $\mathrm{G} 6$ & $\mathrm{G} 7$ & $\mathrm{G} 8$ & $\mathrm{G} 9$ & $\mathrm{G} 11$ & $\mathrm{G} 15$ & $\mathrm{G} 17$ \\
\hline Non-isothermal (TGA), & $\mathrm{X}=0.2-0.8$ & & & & & & \\
$\mathrm{R}^{2}$ & 0.9866 & 0.862 & 0.9843 & 0.9809 & 0.9809 & 0.9809 & 0.9763 & 0.961 & 0.9763 \\
$\mathrm{E}_{\mathrm{a}}(\mathrm{kJ} / \mathrm{mol})$ & 74.4 & - & 97 & 43.7 & 43.7 & 43.7 & 27.9 & 64.3 & 27.9 \\
\hline
\end{tabular}

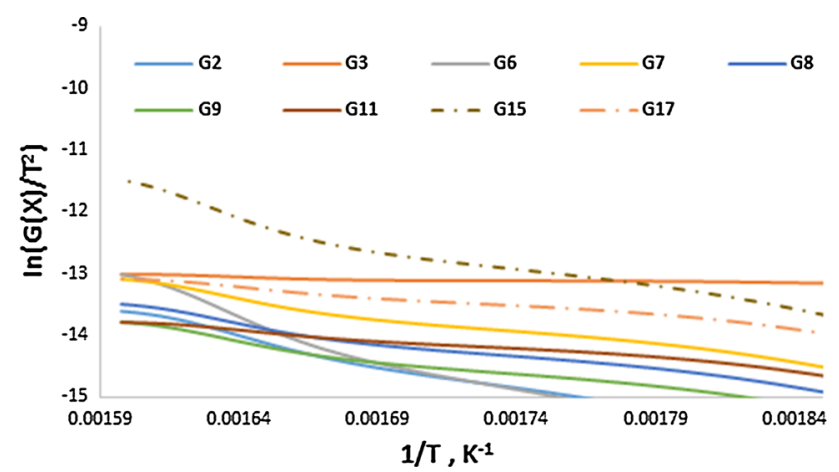

Fig. 9 Correlation of $\ln (\mathrm{G}(\mathrm{X}) / \mathrm{T})$ versus $1 / \mathrm{T}$ for $1180-1400 \mu \mathrm{m}$ particle size for non-isothermal TGA

nineteen potential reaction models shown in Table 1 . The two dimensional diffusion (G2) and three dimensional (G3) model were had the highest fitting accuracy for temperatures between 320 and $451{ }^{\circ} \mathrm{C}$ and 500 and $660{ }^{\circ} \mathrm{C}$ respectively. The data contained in Table 4 verifies the speculation that the decomposition of Olive kernel proceeded with different consecutive mechanisms. The mechanism of two dimensional diffusion could describe the thermal decomposition at low temperature while three dimensional diffusion described it at high temperatures. G2 is the function for a two-dimensional diffusion controlled process, while G3 is Jander's equation for diffusion-controlled solid state reaction kinetics [37].

From straight line plots of the experimental data at different temperatures, the values of $\mathrm{k}$ relating to the Arrhenius function with temperature (see Fig. 12) are shown. From the lnk versus $1 / \mathrm{T}$ plot, the slope $\left(-\mathrm{E}_{\mathrm{A}} / \mathrm{R}\right)$ was used to obtain the values of activation energy for the experiments between $320-451$ and $500-660{ }^{\circ} \mathrm{C}$ for the Olive kernel pyrolysis, giving activation energies of 67.4 and $60.8 \mathrm{~kJ} / \mathrm{mol}$ respectively. Table 4 shows the correlation coefficients, conversion range and the normal logarithm of rate constant obtained from the plot of $G(x)$ against t.
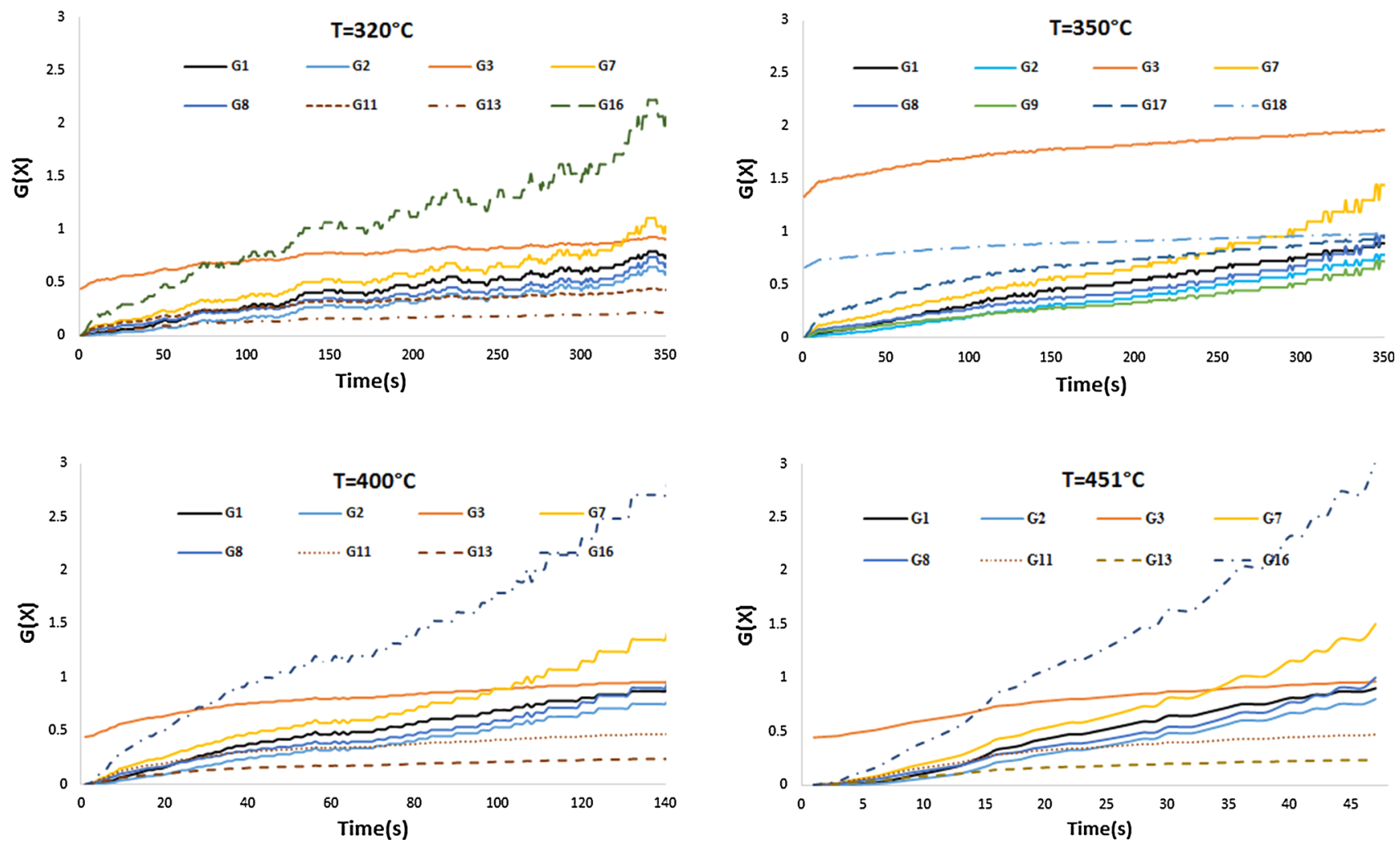

Fig. 10 Correlation of $\mathrm{G}(\mathrm{X})$ versus time at different reaction temperatures for $1180-1400 \mu \mathrm{m}$ particle size (low temperatures) for TGFBR 

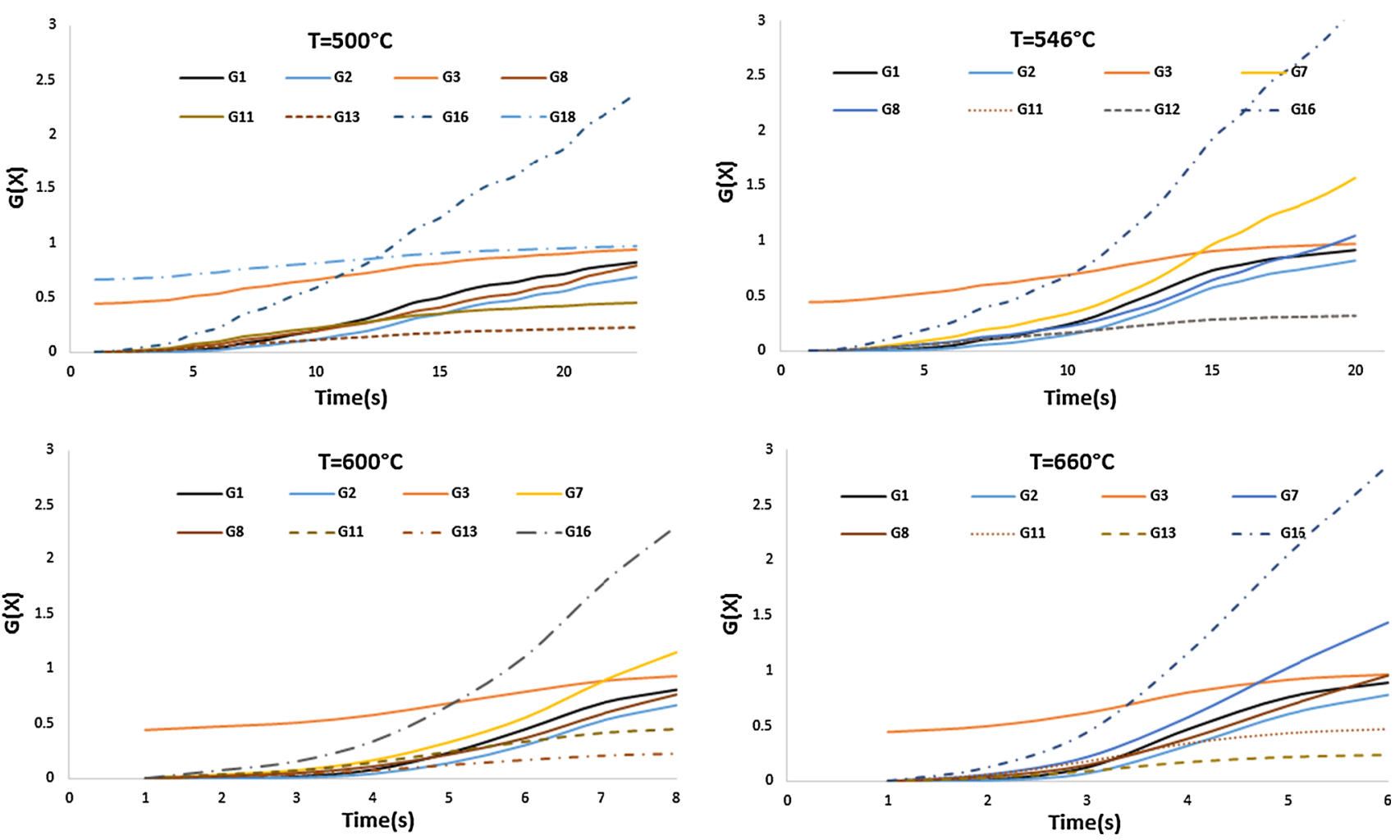

Fig. 11 Correlation of $\mathrm{G}(\mathrm{X})$ versus time at different reaction temperatures for 1180-1400 $\mu \mathrm{m}$ particle size (high temperatures) for TGFBR

Table 4 Reaction model for olive kernel decomposition during fluidised bed isothermal pyrolysis

\begin{tabular}{|c|c|c|c|c|c|c|c|c|c|c|}
\hline$G(X)$ & G1 & $\mathrm{G} 2$ & G7 & G16 & G1 & G2 & G7 & G1 & G2 & G7 \\
\hline Temp $\left({ }^{\circ} \mathrm{C}\right)$ & 320 & 320 & 320 & 320 & 350 & 350 & 350 & 400 & 400 & 400 \\
\hline $\mathrm{R}^{2}$ & 0.972 & 0.974 & 0.962 & 0.962 & 0.99 & 0.993 & 0.97 & 0.978 & 0.993 & 0.975 \\
\hline $\ln K(T)$ & -6.214 & -6.437 & -5.991 & -5.29 & -6.032 & -6.119 & -5.654 & -5.099 & -5.203 & -4.688 \\
\hline$X$ & $0-0.90$ & $0-0.90$ & $0-0.90$ & $0-0.9$ & $0-0.95$ & $0-0.95$ & $0-0.95$ & $0-0.95$ & $0-0.95$ & $0-0.95$ \\
\hline$G(X)$ & G1 & $\mathrm{G} 2$ & G7 & G16 & G1 & G3 & G8 & G3 & G11 & G13 \\
\hline Temp $\left({ }^{\circ} \mathrm{C}\right)$ & 451 & 451 & 451 & 451 & 500 & 500 & 500 & 546 & 546 & 546 \\
\hline $\mathrm{R}^{2}$ & 0.983 & 0.99 & 0.98 & 0.98 & 0.972 & 0.983 & 0.976 & 0.983 & 0.981 & 0.981 \\
\hline $\ln \mathrm{K}(\mathrm{T})$ & -3.825 & -3.973 & -3.467 & -2.77 & -3.135 & -3.68 & -3.28 & -3.422 & -3.952 & -4.24 \\
\hline$X$ & $0-0.95$ & $0-0.95$ & $0-0.95$ & $0-0.95$ & $0-0.90$ & $0-0.90$ & $0-0.90$ & $0-0.95$ & $0-0.95$ & $0-0.95$ \\
\hline$G(X)$ & G3 & & G11 & G13 & & G16 & G3 & & & G13 \\
\hline Temp $\left({ }^{\circ} \mathrm{C}\right)$ & 600 & & 600 & 600 & & 600 & 660 & & & 660 \\
\hline $\mathrm{R}^{2}$ & 0.970 & & 0.80 & 0.970 & & 0.89 & 0.971 & & & 0.970 \\
\hline $\ln \mathrm{K}(\mathrm{T})$ & -2.56 & & -3.31 & -3.343 & & -1.106 & -2.161 & & 258 & -2.95 \\
\hline $\mathrm{X}$ & $0-0.90$ & & $0-0.90$ & $0-0.90$ & & $0-0.90$ & $0-0.95$ & & & $0-0.95$ \\
\hline
\end{tabular}

Comparing the result obtained from fixed bed TGA (non-isothermal) to the fluidised bed (isothermal) in the TGFBR, both exhibit the same mechanism at $<451{ }^{\circ} \mathrm{C}$, and three dimensional diffusion control at $\geq 500{ }^{\circ} \mathrm{C}$. However, the activation energy obtained from the TGA was higher and may be due to the effect of external gas diffusion at lower heating rates [38]. The behaviour of three dimensional diffusion may be associated with greater degradation 

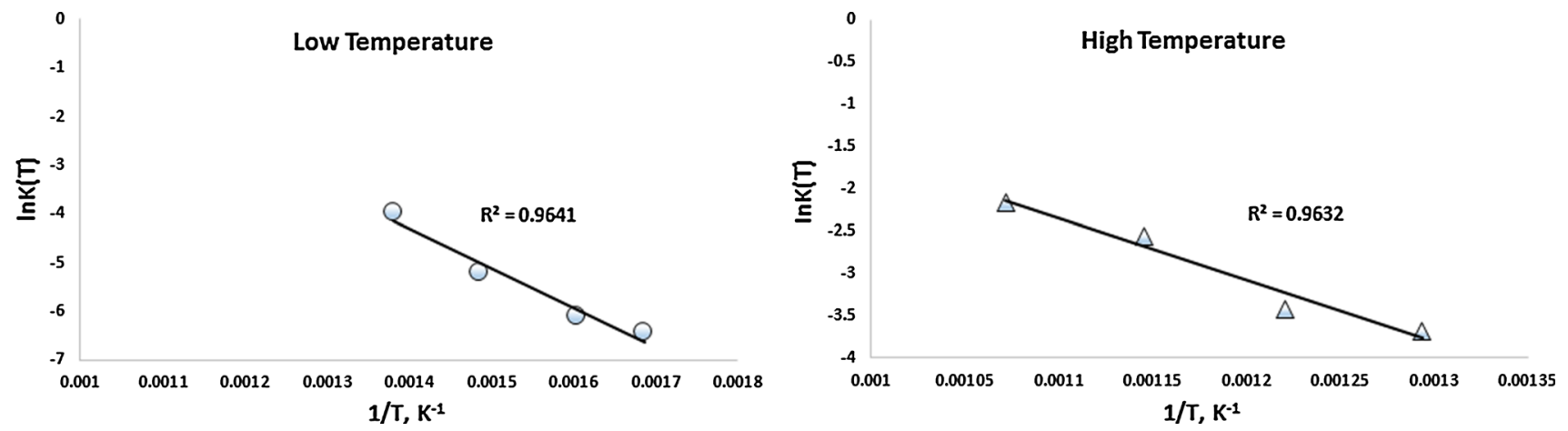

Fig. 12 Arrhenius plot for olive kernel pyrolysis

of hemicellulose and cellulose at high heating rates leading to higher volatility of the main biomass components. In addition, pore lattice defects are considered a significant factor because these defects promote reactivity and diffusion of material [39]. The phenomena of two and three dimensional diffusion has been noticed by Li [40]; where during the study the kinetic mechanism of the reduction reactions of Ferrum niobate were quantified. In addition, the pyrolytic reactions of oil-palm shell at low and high temperature regimes were found to be based on two mechanisms according to Guo and Lua [41]. In comparison to thermogravimetric pyrolysis methods other researchers have also reported different mechanisms and sequences involved in the formation of gas species, for example three dimensional diffusion was found responsible for the production of hydrogen and methane during the pyrolysis process $[12,17]$.

\section{Conclusion}

A laboratory scale thermogravimetric fluidised bed reactor (TGFBR) was developed to measure the reaction kinetics of Olive kernel biomass pyrolysis with fluidising sand mixtures over temperature ranges from 300 to $660{ }^{\circ} \mathrm{C}$ and the results compared with fixed bed pyrolysis in a typical bench top TGA.

It was shown that above $500{ }^{\circ} \mathrm{C}$, the time taken to fully react a $40 \mathrm{~g}$ sample in a bed of $400 \mathrm{~g}$ of sand was less than $10 \mathrm{~s}$. Furthermore, the fast pyrolysis exhibited in the TGFBR provided a uniform temperature inside the reactor supressing external diffusion effects confirmed by little variation in the reaction time above $401 / \mathrm{min}$ flow rate of the fluidising gas.

In the TGA apparatus, particle size had no measurable effect on the reaction rate, whereas a clear dependence of reaction rate on biomass particle size was demonstrated in the TGFBR. In both apparatus, at low heating rates $\left(<451{ }^{\circ} \mathrm{C}\right)$ the reaction time was unaffected by the biomass particle size over the ranges tested. However, for the TGFBR there was a dependence of reaction rate on particle size above $500{ }^{\circ} \mathrm{C}$ when it was observed that the reaction time increased with larger particle sizes.

The pyrolysis reaction kinetics were studied under nonisothermal conditions in the TGA and isothermal conditions in the TGFBR. A two dimensional diffusion model was the controlling mechanism identified with the best fit for the fixed bed TGA with an activation energy of $74.4 \mathrm{~kJ} / \mathrm{mol}$. In comparison, 2-dimensional and 3-dimensional reaction mechanisms gave the best fits to describe the reaction kinetics of the biomass particles over 2 temperature ranges in the TGFBR which could be divided into two stages: the two dimensional diffusion reaction mechanism from 320 to $451{ }^{\circ} \mathrm{C}$ with an activation energy of $67.4 \mathrm{~kJ} / \mathrm{mol}$; and the three dimensional diffusion reaction mechanism from 500 to $660{ }^{\circ} \mathrm{C}$ with an activation energy of $60.8 \mathrm{~kJ} / \mathrm{mol}$.

Bench top TGA analysis of pyrolysis is a rapid and valuable method for comparing the behaviour of biomass reactivity, but the small sample sizes tested and low heating rates places limits on the relevance of results. In comparison, the larger laboratory scale TGFBR fitted with load cells allows detailed measurements at conditions likely to be more representative of those encountered on larger scale systems where heat distribution, heat transfer and mass diffusion effects play a major role in the reactivity of biomass.

Acknowledgments We express our sincere thanks to the Ministry of Higher Education/AL-Nahrain University for their financial support under Contract Number 6052.

Open Access This article is distributed under the terms of the Creative Commons Attribution 4.0 International License (http://creative commons.org/licenses/by/4.0/), which permits unrestricted use, distribution, and reproduction in any medium, provided you give appropriate credit to the original author(s) and the source, provide a link to the Creative Commons license, and indicate if changes were made. 


\section{References}

1. Zabaniotou, A., Stavropoulos, G., Skoulou, V.: Activated carbon from Olive kernels in a two-stage process: industrial improvement. Bioresour. Technol. 99, 320-326 (2008)

2. Skoulou, V., Zabaniotou, A., Stavropoulos, G., Sakelaropoulos, G.: Syngas production from Olive tree cuttings and Olive kernels in a downdraft fixed-bed gasifier. Int. J. Hydrogen Energy 33, 1185-1194 (2008)

3. Yaman, S.: Pyrolysis of biomass to produce fuels and chemical feedstocks. Energy Convers. Manag. 45, 651-671 (2004)

4. de Jong, W., Pirone, A., Wójtowicz, M.A.: Pyrolysis of Miscanthus Giganteus and wood pellets: TG-FTIR analysis and reaction kinetics 2 . Fuel 82, 1139-1147 (2003)

5. Wang, G., Li, W., Li, B., Chen, H.: TG study on pyrolysis of biomass and its three components under syngas. Fuel 87, 552-558 (2008)

6. Caballero, J.A., Conesa, J.A., Font, R., Marcilla, A.: Pyrolysis kinetics of almond shells and Olive stones considering their organic fractions. J. Anal. Appl. Pyrol. 42, 159-175 (1997)

7. Reina, J., Velo, E., Puigjaner, L.: Thermogravimetric study of the pyrolysis of waste wood. Thermochim. Acta 320, 161-167 (1998)

8. Encinar, J.M., González, J.F., González, J.: Fixed-bed pyrolysis of Cynara cardunculus L. Product yields and compositions. Fuel Process. Technol. 68, 209-222 (2000)

9. Park, H.J., Park, Y.-K., Dong, J.-I., Kim, J.-S., Jeon, J.-K., Kim, S.-S., Kim, J., Song, B., Park, J., Lee, K.-J.: Pyrolysis characteristics of Oriental white oak: kinetic study and fast pyrolysis in a fluidized bed with an improved reaction system. Fuel Process. Technol. 90, 186-195 (2009)

10. Yu, J., Yao, C., Zeng, X., Geng, S., Dong, L., Wang, Y., Gao, S., $\mathrm{Xu}, \mathrm{G} .:$ Biomass pyrolysis in a micro-fluidized bed reactor: characterization and kinetics. Chem. Eng. J. 168, 839-847 (2011)

11. Kersten, S.R., Wang, X., Prins, W., van Swaaij, W.P.: Biomass pyrolysis in a fluidized bed reactor. Part 1: Literature review and model simulations. Ind. Eng. Chem. Res. 44, 8773-8785 (2005)

12. Jian, Y., Zhu, J.-H., Feng, G., Duan, Z.-K., Liu, Y.-Y., Xu, G.-W.: Reaction kinetics and mechanism of biomass pylolysis in a microfluidized bed reactor. J. Fuel Chem. Technol. 38, 666-672 (2010)

13. Lv, P., Chang, J., Wang, T., Wu, C., Tsubaki, N.: A kinetic study on biomass fast catalytic pyrolysis. Energy Fuels 18, 1865-1869 (2004)

14. Ollero, P., Serrera, A., Arjona, R., Alcantarilla, S.: Diffusional effects in TGA gasification experiments for kinetic determination. Fuel 81, 1989-2000 (2002)

15. Sait, H.H., Hussain, A., Salema, A.A., Ani, F.N.: Pyrolysis and combustion kinetics of date palm biomass using thermogravimetric analysis. Bioresour. Technol. 118, 382-389 (2012)

16. Guerrero, M.R.B., Marques da Silva Paula, M., Zaragoza, M.M., Gutiérrez, J.S., Velderrain, V.G., Ortiz, A.L., Collins-Martínez, V.: Thermogravimetric study on the pyrolysis kinetics of apple pomace as waste biomass. Int. J. Hydrogen Energy 39, 16619-16627 (2014)

17. Gai, C., Dong, Y., Lv, Z., Zhang, Z., Liang, J., Liu, Y.: Pyrolysis behavior and kinetic study of phenol as tar model compound in micro fluidized bed reactor. Int. J. Hydrogen Energy 40 , 7956-7964 (2015)

18. Haines, P.J.: Principles of Thermal Analysis and Calorimetry, pp. 42-47. Royal society of chemistry, London (2002)

19. Oluoti, K.O., Richards, T., Doddapaneni, T., Kanagasabapathi, D.: Evaluation of the pyrolysis and gasification kinetics of tropical wood biomass. BioResources 9, 2179-2190 (2014)

20. Yu, J., Zeng, X., Zhang, J., Zhong, M., Zhang, G., Wang, Y., Xu, G.: Isothermal differential characteristics of gas-solid reaction in micro-fluidized bed reactor. Fuel 103, 29-36 (2013)
21. Gauthier, D., Zerguerras, S., Flamant, G.: Influence of the particle size distribution of powders on the velocities of minimum and complete fluidization. Chem. Eng. J. 74, 181-196 (1999)

22. Daneshvar, S., Otsuka, K.: Pyrolytic behavior of green macro algae and evaluation of its activation energy. Int. J. Chem. Eng. Appl. 3, 256-263 (2012)

23. Chen, W.-H., Kuo, P.-C.: A study on torrefaction of various biomass materials and its impact on lignocellulosic structure simulated by a thermogravimetry. Energy 35, 2580-2586 (2010)

24. Yang, H., Yan, R., Chen, H., Lee, D.H., Zheng, C.: Characteristics of hemicellulose, cellulose and lignin pyrolysis. Fuel 86, 1781-1788 (2007)

25. Kastanaki, E., Vamvuka, D., Grammelis, P., Kakaras, E.: Thermogravimetric studies of the behavior of lignite-biomass blends during devolatilization. Fuel Process. Technol. 77-78, 159-166 (2002)

26. Jae, J., Tompsett, G.A., Lin, Y.-C., Carlson, T.R., Shen, J., Zhang, T., Yang, B., Wyman, C.E., Conner, W.C., Huber, G.W.: Depolymerization of lignocellulosic biomass to fuel precursors: maximizing carbon efficiency by combining hydrolysis with pyrolysis. Energy Environ. Sci. 3, 358-365 (2010)

27. Hartman, M., Svoboda, K.: Predicting the effect of operating temperature on the minimum fluidization velocity. Ind. Eng. Chem. Process Des. Dev. 25, 649-654 (1986)

28. Kunii, D., Levenspiel, O.: Fluidization Engineering. Elsevier, Amsterdam (2013)

29. Choi, J.H., Suh, J.M., Chang, I.Y., Shun, D.W., Yi, C.K., Son, J.E., Kim, S.D.: The effect of fine particles on elutriation of coarse particles in a gas fluidized bed. Powder Technol. 121, 190-194 (2001)

30. Szekely, J., et al.: Gas Solid Reactions, pp. 65-112. Academic Press, Inc, New york (1976)

31. Bridgwater, A., Meier, D., Radlein, D.: An overview of fast pyrolysis of biomass. Org. Geochem. 30, 1479-1493 (1999)

32. Reschmeier, R., Roveda, D., Müller, D., Karl, J.: Pyrolysis kinetics of wood pellets in fluidized beds. J. Anal. Appl. Pyrol. 108, 117-129 (2014)

33. Zabaniotou, A.A., Kalogiannis, G., Kappas, E., Karabelas, A.J.: Olive residues (cuttings and kernels) rapid pyrolysis product yields and kinetics. Biomass Bioenergy 18, 411-420 (2000)

34. Demirbas, A.: Effects of temperature and particle size on bio-char yield from pyrolysis of agricultural residues. J. Anal. Appl. Pyrol. 72, 243-248 (2004)

35. Czernik, S., Bridgwater, A.: Overview of applications of biomass fast pyrolysis oil. Energy Fuels 18, 590-598 (2004)

36. Scott, D.S., Piskorz, J., Bergougnou, M.A., Graham, R., Overend, R.P.: The role of temperature in the fast pyrolysis of cellulose and wood. Ind. Eng. Chem. Res. 27, 8-15 (1988)

37. Gil, M.V., Casal, D., Pevida, C., Pis, J.J., Rubiera, F.: Thermal behaviour and kinetics of coal/biomass blends during co-combustion. Bioresour. Technol. 101, 5601-5608 (2010)

38. Xu, G., Gao, S., Yu, J., Li, Q., Zhu, J., Duan, Z.: Characteristics and kinetics of biomass pylolysis in a micro fluidized bed reactor. In: 13th International conference on fluidization-new paradigm in fluidization engineering, Hotel Hyundai, Gyeong-ju, Korea, 16-21 May 2010

39. House, J.E.: Principles of Chemical Kinetics, 2nd edn, pp. 229-233. Academic press, London (2007)

40. Yang, Y., Han, J., Zhao, W., Zhang, B.: Kinetic mechanism in the process of carbothermal reduction of ferrum niobate. J. Wuhan Univ. Technol. Mater. Sci. Ed. 30, 918-922 (2015)

41. Guo, J., Lua, A.C.: Kinetic study on pyrolytic process of oil-palm solid waste using two-step consecutive reaction model. Biomass Bioenergy 20, 223-233 (2001) 